\title{
ANALISIS WACANA KRITIS MODEL TEUN A. VAN DIJK PADA IKLAN RAMAYANA DEPARTMENT STORE
}

\author{
(A Critical Discourse Analysis on Ramayana Department Store Advertisement: \\ Teun A. van Dijk's Model)
}

\author{
Fiona Alde Risa, Miftahulkhairah Anwar \\ Pascasarjana Universitas Negeri Jakarta \\ Jalan Rawamangun Muka, Jakarta Timur 13220 \\ Pos-el: FionaAldeRisa_9905820006@mhs.unj.ac.id
}

(Naskah Diterima 25 Januari 2021—Direvisi 13 Agustus 2021—Disetujui 22 September 2021)

\begin{abstract}
Ramayana Department Store advertisement is the advertisement which always visualized before and during Ramadan. Ramayana Department Store ads always shows the unique and impressive ads. One of the Ramayana Department Store advertisement which is mostly watched is "Bahagianya Adalah Bahagiaku". Around 6.6 million viewers have watched the ads in Youtube channel. The reason is the ads can pull the audiences's sympathy. The purpose of this research is to show the hidden meaning of the ads by showing its macro structure, super structure and micro structure. This is a descriptive qualitative research with Teun A. van Dijk model approach. The data will be discourses in the form of a dialogue carried out in the ads. The result of this study show that the ads has some elements of macro structure, super structure and micro structure.
\end{abstract}

Keywords: critical discourse analysis, Ramayana Department Store commercial ads, van Dijk

\begin{abstract}
Abstrak
Iklan Ramayana Departement Store merupakan iklan yang selalu hadir menjelang dan selama Ramadan. Iklan tersebut selalu menghadirkan iklan yang unik, bahkan menyentuh hati. Salah satu iklan yang paling banyak ditonton berjudul "Bahagianya Adalah Bahagiaku". Iklan tersebut sudah ditonton oleh sekitar 6,6 juta orang dalam kanal Youtube. Alasannya iklan tersebut menarik rasa simpati penonton. Tujuan penelitian ini untuk mengungkapkan makna tersembunyi di balik iklan Ramayana Department Store dengan mengungkapkan struktur makro, super struktur, dan struktur mikro. Penelitian ini merupakan penelitian kualitatif deskriptif dengan menggunakan pendekatan model Teun A. van Dijk. Data yang digunakan berupa dialog dalam iklan tersebut. Hasil penelitian menunjukkan bahwa iklan tersebut memiliki unsur struktur makro, super struktur, dan struktur mikro.

Kata kunci: analisis wacana kritis, iklan Ramayana Department Store, van Dijk
\end{abstract}

\section{PENDAHULUAN}

Pada era revolusi industri seperti saat ini pelaku usaha akan menggunakan berbagai cara dalam memasarkan produknya. Salah satunya dengan menggunakan iklan sekreatif dan seunik mungkin agar produk tersebut diminati pembeli. Para pelaku usaha dalam memasarkan produk tidak hanya 
berkaitan dengan bahasa yang persuasif, tetapi visual yang menarik. Pesan yang dihadirkan dalam iklan tersebut juga ikut andil besar dalam pemasaran produk.

Selain menarik minat, banyak pelaku usaha yang berusaha membuat image produk yang dapat diingat oleh konsumennya. Salah satunya iklan yang dibuat Ramayana Department Store. Iklan tersebut tidak jarang menghadirkan suasana yang menyentuh hati sehingga menarik simpati para konsumen.

Iklan Ramayana yang berjudul "Bahagianya Adalah Bahagiaku" mencerminkan hal tersebut. Secara umum iklan tersebut bertema keluarga, tetapi banyak makna tersirat dalam iklan yang perlu dikaji lebih dalam. Iklan tersebut juga memiliki muatan komersial yang tidak terlalu banyak.

Berdasarkan masalah tersebut, penelitian ini akan mengkaji analisis wacana kritis dengan menggunakan model Teun A. van Dijk dalam iklan Ramayana Department Store yang berjudul "Bahagianya Adalah Bahagiaku". Penelitian ini bertujuan untuk mendeskripsikan percakapan dan visualisasi yang dihadirkan dalam iklan tersebut. Hasil analisis diharapkan mengungkap maksud dan makna lain serta menghubungkannya dengan konteks situasi saat itu.

Penelitian ini diharapkan dapat menjadi referensi dalam memperkaya kajian wacana kritis model van Dijk, terutama dalam iklan. Penelitian ini juga diharapkan bisa menjadi salah satu cara dalam melihat sebuah makna dalam sebuah wacana secara kritis.

Iklan Ramayana yang akan dikaji dalam penelitian ini merupakan iklan produksi tahun 2017. Iklan tersebut juga dapat ditonton di kanal Youtube Ramayana Department Store. Iklan Ramayana yang berjudul "Bahagianya Adalah Bahagiaku" merupakan video iklan yang paling banyak ditonton dibandingkan dengan iklan Ramayana yang lain.

Iklan tersebut menceritakan seorang ibu yang sudah satu tahun tinggal bersama anak dan cucunya. Ibu tersebut selalu menganggap setiap hari adalah Ramadan. Hal tersebut disebabkan oleh trauma akibat kepergian suaminya satu tahun lalu. Terhentinya ingatan ibu tersebut mengakibatkannya selalu menyuruh anak dan cucunya puasa, tarawih, dan membeli baju Lebaran. Anak dan cucu ibu itu tidak ada yang berani menjelaskan kepada ibunya lantaran khawatir ibunya akan bersedih kembali.

$\begin{array}{ccc}\text { Penelitian } & \text { mengenai } & \text { iklan } \\ \text { Ramayana } & \text { Department } & \text { Store }\end{array}$
sebelumnya tidak banyak dilakukan. Penelitian Adrian yang berjudul "Pengaruh Terpaan Iklan Youtube Ramayana 2017 Versi Bahagianya Adalah Bahagiaku terhadap Citra Merek" menemukan bahwa iklan berpengaruh terhadap citra mereka (Adrian \& Nurhayati, 2018).

Penelitian mengenai wacana kritis model Teun A. van Dijk telah dilakukan sebelumnya oleh Saleh. Ia melakukan penelitian yang berjudul "Analisis Wacana Kritis Hukuman Salah Alamat pada Acara Mata Najwa”. Saleh mengungkapkan bahwa analisis struktur makro secara garis besar membahas kasus Baiq Nuril yang telah menjadi korban atas kasus pencemaran nama baik. Kemudian, dalam analisis super struktur, dialog dibagi menjadi tiga bagian, yaitu pendahuluan, isi, dan penutup. Dalam analisis struktur mikro, ditemukan beberapa metafora yang digunakan oleh Najwa Shibab (Saleh, 2020).

Penelitian lainnya mengenai analisis wacana kritis dilakukan oleh Alfiyani dengan judul "Analisis Wacana Perbedaan Agama dan Budaya dalam Film Bidadari Mencari Sayap". Hasil 
penelitian tersebut mengungkapkan bahwa struktur makro dalam film ini mengangkat tema perbedaan agama dan budaya. Kemudian dalam struktur mikro film ini terdapat tiga komponen, yaitu sintaksis, semantik, dan stilistika. Super struktur dalam film ini ialah konflik keluarga yang disebabkan perbedaan agama dan budaya (Alfiyani, 2021).

Penelitian lain yang menggunakan analisis wacana kritis di antaranya pernah dilakukan oleh Fitriana dengan judul "Analisis Wacana Kritis Berita Online Kasus Penipuan Travel Umrah (Model Teun A. van Dijk)", Ningsih dengan judul "Analisis Wacana Kritis pada Novel Ayat-Ayat Cinta 2 (Model Teun A. van Dijk)", dan Firdasari yang berjudul "Analisis Wacana Talk Show Program Mata Najwa di Metro TV" (Firdasari, 2018; Fitriana, 2019; Ningsih et al., 2019).

Berbeda dari penelitian-penelitian sebelumnya, pada penelitian ini peneliti menganalisis iklan Ramayana Department Store yang berjudul "Bahagianya Adalah Bahagiaku" dengan menggunakan model Teun A. van Dijk. Dari penelitian-penelitian yang sudah dilakukan, belum ada penelitian yang secara khusus membahas iklan Ramayana Department Store.

Iklan merupakan sarana yang digunakan dalam mempromosikan suatu produk. Iklan biasanya berisi informasi yang menarik minat konsumen agar membeli produk yang dipromosikan. Iklan haruslah bersifat persuasif sehingga konsumen tertarik pada produk yang ditawarkan.

Dalam perkembangannya, iklan terus mengalami perubahan ke arah yang lebih baik. Dari yang semula berbentuk tulisan, sekarang banyak iklan berbentuk gambar hingga audiovisual. Iklan berbentuk audiovisual tidak menghilangkan bahasa yang ada pada iklan, tetapi menggantinya dengan bahasa lisan. Iklan audiovisual memiliki kelebihan dibanding tulisan karena masyarakat modern lebih menyukai sesuatu yang bersifat visual (Andrianto et al., 2019).

Iklan merupakan sebuah cara komunikasi yang khas. Iklan mencoba mengomunikasikan citra secara maksimal dengan menggunakan waktu yang relatif singkat sehingga sasaran dapat dicapai dan bisa menjamin keuntungan dari perusahaan (Winingsih, 2017). Senada dengan itu, Nurjanah mengungkapkan bahwa periklanan adalah cara mengomunikasikan informasi yang bersifat persuasif mengenai produk, baik ide, jasa, maupun barang dengan menggunakan media (Nurjanah \& Pratiwi, 2019). Iklan menjadi strategi pemasaran yang efektif dalam memberikan informasi, baik itu produk maupun jasa, kepada konsumen (Insani et al., 2019).

Wicaksono menjelaskan bahwa kekuatan utama iklan adalah pada penggunaan bahasa, gambar, dan penempatan unsur-unsur lain yang ada di dalamnya (Wicaksono, 2019). Oleh karena itu, bahasa dalam iklan memiliki kaidah kebahasaan tersendiri.

Jadi, dapat disimpulkan dari beberapa pendapat tersebut bahwa iklan merupakan media yang digunakan dalam menyampaikan informasi yang bersifat memengaruhi. Dalam membuat iklan, pembuatnya perlu memiliki kreativitas yang tinggi agar iklan yang dibuat dapat menarik perhatian konsumen.

Selain memiliki perbedaan jenisnya, iklan juga memiliki fungsi yang berbeda. Pertama, fungsi literal, yaitu sebagai penyedia informasi nyata yang berdasarkan fakta, baik informasi produk maupun jasa. Fungsi yang kedua ialah fungsi simbolik sebagai penjelasan mengenai gambar atau tampilan yang memiliki makna tertentu (Purwaka et al., 2020). 
Setiap iklan selalu menghadirkan keunggulan dan perbedaan dari produk lain. Ada juga contoh iklan yang menarik hati konsumen dengan cara menggerakkan perasaan atau membuat konsumen berpikir ketika menonton iklan tersebut. Banyak iklan yang tidak menjelaskan kualitas produknya. Akan tetapi, iklan tersebut menjelaskan hal lain yang memiliki nilai bagi seseorang yang melihat.

Analisis wacana kritis memandang bahasa bukan berdasarkan struktur, melainkan sebagai karakter yang memiliki hubungan dengan struktur budaya. Analisis wacana kritis mempelajari relasi kuasa dalam sebuah wacana kemudian melihat hubungan wacana tersebut dengan masyarakat atau budaya (Anwar, 2010).

Analisis wacana kritis adalah pendekatan konstruktivis sosial yang memiliki pandangan bahwa makna bersifat historis dan pengetahuan tercipta dari interaksi sosial (Andrianto et al., 2019). Analisis wacana kritis merupakan proses penguraian dalam mengkaji suatu teks (dimensi sosial) yang bertujuan untuk memperoleh hal yang diinginkan dari pihak yang menciptakan wacana tersebut. Analisis wacana kritis menyediakan teori dan metode yang dapat digunakan dalam melakukan kajian empiris mengenai hubungan antara wacana, perkembangan sosial, dan budaya (Firmansyah, 2018).

Analisis wacana kritis mempelajari kekuatan sosial dan konteks sosial, termasuk politik yang ada pada wacana (Goziyah, 2019). Analisis wacana kritis terfokus pada dua hal, yaitu praktikpraktik diskursif yang menghadirkan representasi mengenai dunia subjek serta hubungan sosialnya dan peran dari praktik tersebut untuk memantapkan kepentingan politik tertentu (Saputra, 2019).
Perbedaan mendasar analisis wacana kritis model van Dijk, yaitu pergeseran penting dalam memahami teks yang berarti perubahan dari teks yang dipahami sebagai teks yang terkait dengan konteksnya. Analisis wacana kritis bertujuan untuk mengungkapkan ideologi berdasarkan penggambaran positive self-representation dan negative self-representation (Fauzan, 2014).

Menurut van Dijk, wacana tidak hanya berfokus pada analisis, tetapi harus dilihat proses suatu teks dibuat sehingga diperoleh pengetahuan bagaimana suatu teks bisa semacam itu. Wacana menurut van Dijk memiliki tiga dimensi, yaitu teks, kognisi sosial, dan konteks sosial (Darma, 2009; Jufanny \& Girsang, 2020).

Teks memiliki tiga komponen di dalamnya, yaitu struktur mikro, super struktur, dan struktur makro. Selanjutnya, kognisi sosial yang mencakupi pengetahuan, kesadaran, dan prasangka pencipta wacana terhadap suatu peristiwa. Kemudian, konteks sosial, wacana berdasarkan makna yang dipahami secara umum di masyarakat.

Struktur makro merupakan makna global dari sebuah wacana. Tema merupakan gambaran umum mengenai pendapat yang disampaikan oleh seseorang. Tema dapat menunjukkan konsep dan hal utama dari sebuah iklan. Super struktur berupa alur dari pendahuluan sampai akhir.

Alur tersebut dapat menunjukkan bagian dalam sebuah teks yang disusun secara sistematis sehingga dapat membentuk kesatuan arti. Struktur mikro biasanya lebih kompleks dibanding struktur yang lain. Struktur mikro terdiri atas analisis semantik, analisis kalimat, analisis leksikon, dan analisis stilistika (Musyafa'ah, 2017).

Dapat disimpulkan bahwa wacana kritis merupakan suatu analisis yang difokuskan pada kajian terhadap dimensi 
sosial yang ada di balik wacana yang dihadirkan serta tujuan di baliknya, seperti politik, konteks sosial, dan budaya.

\section{METODE PENELITIAN}

Metode yang digunakan dalam penelitian ini ialah deskriptif kualitatif dengan metode analisis isi. Data yang digunakan ialah wacana berupa dialog yang dilakukan dalam iklan tersebut. Analisis data dilakukan menggunakan teori AWK model van Dijk yang membagi wacana menjadi tiga komponen, yaitu struktur makro, super struktur, dan struktur mikro.

Teknik yang digunakan dalam pengumpulan data ialah menyimak dan mencatat iklan Ramayana Department Store yang berjudul "Bahagianya Adalah Bahagiaku". Peneliti menyimak iklan tersebut melalui Youtube kemudian mencatat setiap percakapan yang dilakukan oleh model dalam iklan. Hasil catatan tersebut kemudian dianalisis dengan mengacu pada teori van Dijk.

\section{PEMBAHASAN}

\section{Struktur Makro}

Secara umum iklan Ramayana tersebut membahas seorang nenek yang selalu menyuruh anak, menantu, dan cucunya untuk melaksanakan ibadah dan kegiatan yang biasa dilakukan selama bulan Ramadan. Pada saatnya, menantu dan cucu tersebut enggan melaksanakan perintahnya melaksanakan ibadah di bulan Ramadan. Alasan menantu enggan berpuasa karena bulan tersebut bukanlah bulan Ramadan. Keluarga tersebut menutupi semuanya agar sang nenek tidak terluka mengingat trauma setelah ditinggal suaminya untuk selamalamanya. Sang nenek kemudian diajak ke suatu tempat. Ternyata, tempat tersebut ialah makam suaminya.

Secara garis besar, tema dalam iklan tersebut ialah kasih sayang keluarga dengan menambahkan suasana Ramadan dalam latar waktunya. Dapat dilihat bahwa iklan tersebut hadir dengan tema yang berkaitan dengan keluarga dan suasana yang biasa hadir pada bulan Ramadan. Hal tersebut bertujuan untuk menyadarkan masyarakat agar menyayangi keluarga dan membahagiakannya.

Iklan tersebut juga menampilkan beberapa adegan sahur, salat Tarawih, dan belanja pakaian. Iklan tersebut memiliki tujuan menarik simpati konsumen agar saling menyayangi anggota keluarga dengan cara, salah satunya, berbelanja ke Ramayana Department Store.

\section{Super Struktur}

Analisis super stuktur berhubungan dengan kerangka dan dialog-dialog yang digunakan dalam iklan tersebut. Super struktur mengacu kepada makna setiap kata atau kalimat yang diutarakan dan bagian-bagian dalam teks, seperti pendahuluan, isi, dan penutup.

Iklan tersebut memiliki judul/unsur summary, yaitu "Bahagianya Adalah Bahagiaku", sedangkan unsur lead merupakan hal-hal yang menggiring konsumen saat menyaksikan iklan.

\section{Data 1}

"Bapak gak puasa dulu, deh, hari ini."

Cara bapak dalam menyampaikan hal tersebut sangat serius sehingga pada awal cerita, konsumen akan berpikir bahwa bapak tersebut lalai karena tidak menjalankan ibadah puasa. Kalimat pembuka dalam iklan tersebut dapat menggiring konsumen sebab konteks situasi saat itu bulan Ramadan. Umat 
Islam wajib hukumnya melaksanakan ibadah puasa.

Kalimat tersebut membuat masyarakat bertanya-tanya alasan bapak tidak melaksanakan ibadah puasa. Padahal, bapak merupakan laki-laki yang memiliki tubuh sehat. Kalimat tersebut bertujuan menarik minat masyarakat untuk menggali lebih dalam maksud dialog tersebut.

Bagian isi dalam iklan itu difokuskan pada kegiatan-kegiatan yang dilakukan pada bulan Ramadan.

\section{Data 2}

Nenek : "Panji, ayo puasa"

Panji : "Kan laper, Bu." (Berbicara kepada sang ibu)

Ibu : "Udah, kamu makan di belakang, ya."

Dalam dialog tersebut, sang nenek berusaha mengingatkan keluarganya untuk melaksanakan ibadah puasa. Berdasarkan dialog di bagian isi, penonton digiring untuk berpikir bahwa menantu dan cucu sang nenek tersebut memiliki sikap yang kurang baik. Selain itu, dialog dalam iklan tersebut membahas topik puasa yang disebabkan konteks situasi saat iklan tersebut ditayangkan, yaitu bulan Ramadan. Hal tersebut bertujuan mengaitkan konteks dalam iklan agar sesuai dengan konteks situasi saat itu sehingga pesan yang ingin disampaikan lebih mudah dan tepat sasaran.

\section{Data 3}

Nenek : "Bapakmu belum punya, lo, baju Lebaran. Kamu gak beli?"

Petugas Ramayana: "Bu, dateng lagi?"

Berbeda dengan iklan pada umumnya yang selalu mempromosikan produk dengan mendeskripsikan kelebihan atau perbedaannya dengan produk lain, dalam iklan ini promosi dilakukan secara implisit. Kalimat, "Bu, dateng lagi," yang dikatakan petugas menandakan bahwa keluarga tersebut selalu membeli baju di Ramayana.

Penggunaan kalimat tersebut merupakan bentuk promosi bahwa untuk membahagiakan keluarga, salah satunya dapat dilakukan dengan membeli pakaian di Ramayana. Iklan tersebut ditutup dengan kilas balik dan prolog tentang alasan keluarga tersebut berpuasa dan melakukan kegiatan yang biasanya ada pada bulan Ramadan.

Segmen penutup dari iklan tersebut ialah seluruh anggota keluarga mengajak sang nenek ke pemakaman umum dan menjelaskan baik-baik kepadanya dengan kalimat terakhir di bawah ini.

\section{Data 4}

"Jangan pernah berhenti membahagiakan orang yang kita cintai karena itu keren."

Bagian penutup iklan memiliki pesan yang dalam yang berfungsi untuk menarik rasa simpati para konsumen. Penutup iklan tersebut memiliki keterkaitan dengan dialog-dialog sebelumnya. Penutup tersebut menjadi simpulan atas semua peristiwa yang terjadi dalam iklan sehingga membentuk koherensi yang baik.

\section{Struktur Mikro}

\section{Analisis Semantik}

Dalam analisis menggunakan teori van Dijk, yang menjadi fokusnya adalah latar, detail, maksud, dan praanggapan.

\section{Latar}

Latar berkaitan dengan penentuan arah pandangan masyarakat terhadap iklan yang disajikan. Dengan adanya latar, penulis dapat mengetahui maksud atau pesan yang ingin disampaikan dalam iklan tersebut. Hal yang melatarbelakangi adanya iklan 
Ramayana dengan judul "Bahagianya Adalah Bahagiaku" ialah konteks situasi saat itu, yaitu bulan Ramadan. Secara garis besar, latar iklan Ramayana tersebut membawa pandangan masyarakat terhadap sikap-sikap yang perlu diteladani dan diikuti untuk membahagiakan keluarga.

\section{Detail}

Unsur detail dalam iklan tersebut ialah menonjolkan karakter anak, menantu, dan cucu dari sang nenek. Keluarga tersebut digambarkan memiliki sikap yang kurang sopan dan tidak menuruti perkataan sang nenek. Penonjolan karakter keluarga tersebut digambarkan secara detail, mulai dari menolak sahur, tidak puasa, hingga tidak salat tarawih. Dalam penutup iklan, baru dijelaskan alasan keluarga tersebut bersikap seperti itu.

\section{Maksud}

Maksud di sini mengacu kepada sifat informasi yang disajikan dalam iklan. Secara garis besar, pesan yang diberikan dalam iklan bersifat eksplisit dan dapat dipahami oleh masyarakat umum. Muatan promosinya sendiri bersifat implisit. Iklan tidak secara jelas mempromosikan produknya.

Data (3) secara tidak langsung bertujuan mengajak konsumen untuk membeli baju Lebaran di Ramayana. Hal tersebut didasarkan pada latar tempat pengucapan kalimat tersebut. Selain itu, Ramayana selalu memberikan tagar dalam setiap iklannya yang memiliki maksud implisit, seperti \#bahagiahaksegalabangsa.

\section{Praanggapan}

Praanggapan merupakan fakta yang belum bisa dibuktikan kebenarannya. Iklan ini memiliki praanggapan bahwa seluruh anggota dalam keluarga tersebut tidak menghargai sang nenek dan justru akan mengajak sang ibu untuk ke panti wreda.

\section{Data 5}

Ayah : "Kita bawa, deh, Ibu."

Ibu : "Yakin?"

Ayah : "Iya. Катu yang ngomong, ya. Aku gak tega."

Dalam dialog tersebut, tentu saja awalnya masyarakat mengira bahwa sang nenek akan dibawa ke panti wreda. Keluarga tersebut merasa terganggu atas kehadiran nenek di rumah mereka. Kenyataannya, keluarga tersebut menyembunyikan sesuatu demi kebaikan sang nenek. Dalam dialog pada data (5) keluarga tersebut mengajak sang nenek ke suatu tempat yang ternyata tempat pemakaman umum.

\section{Analisis Sintaksis}

Komponen sintaksis yang dianalisis ialah bentuk kalimat, koherensi, pengingkaran, dan kata ganti.

\section{Bentuk Kalimat}

Kalimat dalam iklan tersebut menggunakan pola induktif.

\section{Data 6}

"Bapak tuh udah lama gak ada, Bu. Ingatan Ibu terhenti saat Bapak meninggal Ramadan tahun lalu. Sejak itu, buat Ibu setiap hari adalah Ramadan."

\section{Koherensi}

Penanda kohesi yang digunakan berupa pronomina kita seperti dalam ungkapan "Sejak Ibu tinggal di rumah, hidup kita berubah" dan penanda waktu, seperti dalam ungkapan "Sejak itu, buat Ibu setiap hari adalah Ramadan".

Pengingkaran 
Tujuan dari iklan tersebut memang tidak digambarkan secara jelas, tetapi ada latar tempat dengan percakapan seperti yang tercantum pada data (3). Ucapan pegawai Ramayana secara implisit mengajak konsumen membeli baju di Ramayana.

\section{Kata Ganti}

Kata ganti yang terdapat dalam iklan ini ialah nama orang, Panji, dan anakmu yang mengacu kepada Panji.

\section{Analisis Stilistika}

Stilistika merupakan kajian yang berkaitan dengan penggunaan gaya bahasa yang digunakan dalam sebuah wacana. Stilistika biasa digunakan untuk memberikan kesan berbeda atau ciri khas yang biasanya disampaikan oleh penutur.

Kata bawa umumnya merujuk kepada suatu benda. Akan tetapi, dalam data (5), kata bawa merupakan kata yang memiliki makna yang sama dengan ajak. Kata gak ada dalam data (6) bermakna sudah meninggal. Ciri yang lain ialah sang nenek selalu menyatakan kalimat tanya, misalnya "Suamimu mana?" dan "Terus Bapakmu?”. Banyaknya kalimat tanya yang sering digunakan oleh sang nenek menjadi ciri stilistika yang khas.

\section{Analisis Retorik}

Analisis retorik berfokus pada metafora atau pengandaian yang digunakan dalam sebuah wacana. Unsur retorik juga dapat dilihat dari ekspresi sang penutur. Unsur metafora tidak ditemukan dalam iklan tersebut.

\section{PENUTUP}

Berdasarkan analisis, penulis menemukan ketiga unsur yang dibahas oleh van Dijk dalam wacana kritis, seperti struktur makro, super struktur, dan struktur mikro. Dari analisis tersebut dapat disimpulkan bahwa Ramayana memasarkan produknya dengan cara yang implisit. Tidak ada kalimat dalam wacana iklan yang bersifat persuasif. Namun, jika ditinjau lebih dalam, Ramayana memengaruhi konsumen dengan menarik rasa empatinya. Selain menarik empati, Ramayana menggunakan latar tempat yang selalu berada di Ramayana dan menggunakan tagar \#bahagiahaksegalabangsa \#kerenhaksegalabangsa. Jika ingin bahagia dan keren sebagai bangsa Indonesia, berbelanjalah di Ramayana.

\section{DAFTAR PUSTAKA}

Adrian, S. W. \& Nurhayati, I. K. (2018). Pengaruh Terpaan Iklan Youtube Ramayana Ramadan 2017 Versi Bahagianya Adalah Bahagiaku terhadap Citra Merek. EProceedings of Management, 5(1), 1474.

Alfiyani, C. (2021). Analisis Wacana Perbedaan Agama dan Budaya dalam Film "Bidadari Mencari Sayap." Suar Betang, 16(1), 3948.

https://doi.org/10.26499/surbet.v16 i1.215

Andrianto, T., Ariyanti, F., Prasiska, D. W., Prabawa, A. H., \& Waljinah, S. (2019). Analisis Wacana Kritis pada Iklan Rokok Djarum 76. The 10th University Research Colloqium 2019 Sekolah Tinggi Ilmu Kesehatan Muhammadiyah Gombong, 121-127.

Anwar, Mi. (2010). Wahhabi Versus Islam Liberal: Pembacaan Analisis Wacana Kritis Teks "Rendah diri Kaum Wahhabi". Jurnal Bahasa dan Sastra, 10(15), 1-9.

Darma, Y. A. (2009). Analisis Wacana Kritis. Bandung: Yrama Widya.

Fauzan, U. (2014). Analisis Wacana 
Kritis dari Model Faiclough hingga Mills. 7(1), 219-232.

Firdasari, I. C. (2018). Analisis Wacana Talk Show Program Mata Najwa "Lelakon Antasari Azhar" di Metro Tv. Suar Betang, 13(1), 18.

https://doi.org/10.26499/surbet.v13 i1.39

Firmansyah, M. B. (2018). Analisis Wacana Kritis: Dimensi Sosial dalam Novel Negeri Para Bedebah Karya Tere Liye. 4, 63-71. https://doi.org/10.31227/osf.io/9tm av

Fitriana, R. A. (2019). Analisis Wacana Kritis Berita Online Kasus Penipuan Travel Umrah (Model Teun a. van Dijk). BASINDO : Jurnal Kajian Bahasa, Sastra Indonesia, dan Pembelajarannya, $3(1)$, 44-54. https://doi.org/10.17977/um007v3i $12019 \mathrm{p} 044$

Goziyah, G. (2019). Analisis Wacana Kritis Film Rudy Habibie dalam Meningkatkan Kemampuan Berpikir Kritis Mahasiswa. Diksa: Pendidikan Bahasa dan Sastra Indonesia, 5(2), 77-85. https://doi.org/10.33369/diksa.v5i2 .9914

Insani, H. R., Anggraini, N., \& Purawinangun, I. A. (2019). Wacana Kritis pada Iklan Proviver Tahun 2018. Jurnal Sasindo Unpam, 7, 573-574.

Jufanny, D., \& Girsang, L. R. M. (2020). Toxic Masculinity dalam Sistem Patriarki (Analisis Wacana Kritis van Dijk Dalam Film "Posesif"). Jurnal Semiotika, 14(1), 8-23.

Musyafa'ah, N. (2017). Analisis Wacana Kritis Model Teun A. van Dijk "Siswa Berprestasi Jadi Pembunuh." MODELING: Jurnal Program Studi PGMI, 4(2), 203211.
Ningsih, W., Sinar, T. S., \& Zein, T. T. (2019). Analisis Ideologi pada Novel "Ayat-Ayat Cinta 2": Analisis Wacana Kritis Model van Dijk. MEDAN MAKNA: Jurnal Ilmu Kebahasaan dan Kesastraan, 17(2), 99. https://doi.org/10.26499/mm.v17i2 .2133

Nurjanah, N., \& Pratiwi, R. A. (2019). Citra Perempuan Berhijab dalam Iklan Sampo: Sebuah Kajian Pragmatik. Jurnal Pena Indonesia, 5(2), 69-78.

Purwaka, A., Diman, P., Maleyati, I. N., Bahasa, P., Universitas, F., \& Raya, P. (2020). Relasi Sistem Tanda Verbal dan Tanda Visual pada Iklan Rokok di Youtube. Suar Betang, 15(2), 233-243.

Saleh, R. (2020). Analisis Wacana Kritis "Hukuman Salah Alamat" pada Acara Mata Najwa. Suar Betang, 15(2), 181-197.

Saputra, P. S. (2019). Analisis Wacana Kritis Iklan Film Pendek Line Versi "Ada Apa dengan Cinta?" Ars: Jurnal Seni Rupa dan Desain, 22(1), 16-24. https://doi.org/10.24821/ars.v22i1. 2764

Wicaksono, A. (2019). Analisis Wacana Kritis Iklan Operator Seluler (Teks dan Konteks Iklan XL dengan Kartu As). Ksatra: Jurnal Kajian Bahasa Dan Sastra, 1(1), 1-14.

Winingsih, I. (2017). Realisasi Register dalam Iklan "Aqua". Coference on Language and Language Teaching, 491-497. 